
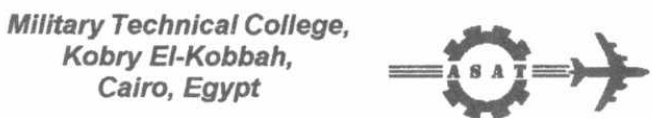

$9^{\text {th }}$ International Conference

On Aerospace Sciences \&

Aviation Technology

\title{
EXPERIMENTAL INVESTIGATION OF RECOIL FORCE FOR AUTOMATIC SMALL ARMS AND THE EFFECT OF USING MUZZLE BRAKE
}

\author{
Abu-Elkhair* M. S., Sherif* H. A., Said* S. M.
}

\begin{abstract}
:
The function cycle of an automatic weapon is the key point for investigation of all activities carried out during firing [1]. Knowing the force of recoil and the corresponding action time helps in studying the dynamic characteristics of a weapon. In old techniques; recording of function cycle depends mainly on studying the motion of the breech block carrier, upon which basic dynamic characteristics are berried and can not be represented. These omitted characteristics represent impacts, strain resulting from impacts, as well as the forces causing instability of weapon during firing [2]. The difficulty in recording these phenomena is referred to the difficulties of mounting the sensing elements on highly retarding components; especially in high caliber weapons.

In this paper; a new technique based on recording strain signals resulting from impacts during motion of weapon mechanism is used. It allows recording all vital activities of function cycle and facilitates the analysis of forces generated from firing. The study allows to record and to analyze one of the most effective forces, this force is referred to as the recoil force of the whole weapon $[3,4]$, it also helps in determination of the efficiency of muzzle devices used to reduce the effect of this force [5]. It has been taken into consideration that the measuring set up allows recording free and braked recoil force.
\end{abstract}

\section{KEY WORDS}

Muzzle devices, Muzzle brake, Recoil force, Automatic small arms, Discharging of gases, Pressure wave, Stress waves, Function cycle,

* Egyptian Armed Forces. 


\section{1- INTRODUCTION:}

The measuring setup is constructed of two main blocks, the first one belongs to the weapon mounting devices, while the second block explains the set of electronic devices used in measurement, as well as the sensing device used for detection of the stress signal.

Celens and Plovie [6], studied the recoil force of automatic weapons, two measurements configurations were used, one for obtaining recoil displacement and acceleration versus time while the second was used for measuring recoil force versus time. The operating mechanism of the weapon itself influences the recoil parameters considerably. Furthermore, a butt stock device enables the comparison between the recoil measured on a test fixture and the real recoil parameters. Besides, it has been assured that the recoil impulse can be reduced by more than 20 $\%$ by means of a specifically designed muzzle brakes.

\section{2-EXPERIMENTAL TEST RIG :}

An experimental set up is constructed for the investigation of recoil force of the Automatic Rifle (7.62 $399 \mathrm{~mm} \mathrm{AKM})$. In spite of the difficulties in recording the function cycle and recoil force of the mentioned weapon, the measuring set up allows measurement in case of single and automatic firing. A series of impacts, each one explains a certain phenomena taking place during firing. General view of the test rig and the instrumentation is given in Fig. 1 The weapon is firmly fixed on a special test stand, such that the fixation guarantees rigid clamping of the weapon during firing, clamping fixes the barrel group as well as the casing of the weapon and satisfies the following requirements:

- It does not allow motion of mounting carrier in lateral directions.

- Barrel and muzzle point are free to move in all directions.

- The system of the whole weapon allows axial retardation.

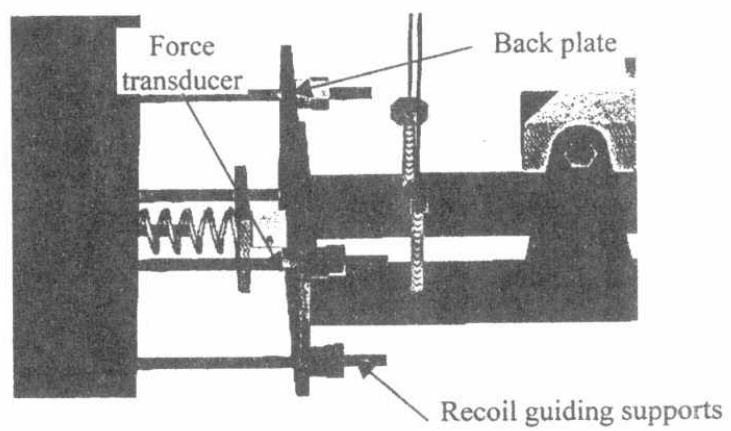

Fig.1 General view of the experimental set up 


\section{2-1 Muzzle brake:}

It is an additional attachment mounted on the muzzle point of the barrel in order to reduce the effect of recoil energy on the stability of weapon, this in turn affects the accuracy of firing. The proposed muzzle brake is specially designed for small caliber automatic weapons, for more details see Fig. 2.

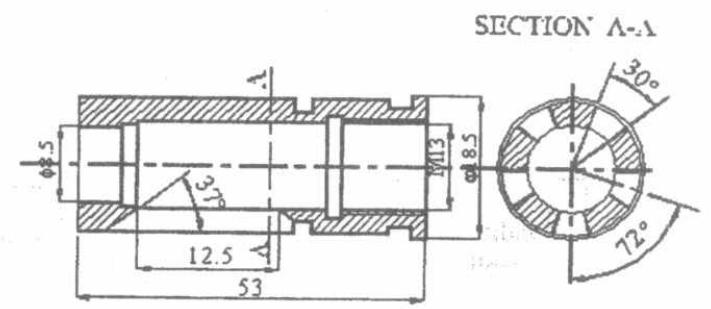

Fig.2 Muzzle brake cross-section in longitudinal section

\section{2-2 Measuring devices:}

The measuring devices which are used for experimental investigations of recoil force for automatic rifle AKM 7.62×39 mm are listed as follows (see Fig. 3.):

1- Force transducer (type $8200 \mathrm{~B} \& \mathrm{~K}$ ) connected to conditioning amplifier (type 2626 B\&K).

2- 4 channels FM tape recorder (type 7003 B\&K) connected to the output of measuring amplifier and conditioning amplifier.

3-2-channel dynamic frequency analyzer (type 3562A HP) connected to the output of the tape recorder.

4- Floppy unit (type $9122 \mathrm{Hp}$ ) connected to 2-channel dynamic analyzer.

5- X-Y plotter (type $2032 \mathrm{HP}$ )

6- Data acquisition card 16 channel (type cb DAS 16)

7- Personnel computer and printer.

In order to measure the recoil force, a piezoelectric forc e transducer (type 8200 $\mathrm{B} \& \mathrm{~K}$ ) is assembled against a spring to the back plate, which is fixed in the fixture as shown in Fig. 1 The recoil force signal obtained was amplified through a conditioning amplifier (type $2626 \mathrm{~B} \& \mathrm{~K}$ ). These measurements also carried out in two techniques as follows:

$1^{\text {st }}$ Technique of measurements: The amplified signal are analyzed using Data Acquisition card (Type $\mathrm{Cb}$ Das 16) plugged into personal computer and printed using Hp Laser printer 2100.

2nd Technique of measurements: The recorded signals using 4 channels FM tape recorder (type $7003 \mathrm{~B} \& \mathrm{~K}$ ) are analyzed in time domain using the system frequency analyzer (type 3562A HP). The obtained signals stored using a floppy unit (type $9122 \mathrm{HP}$ ). 


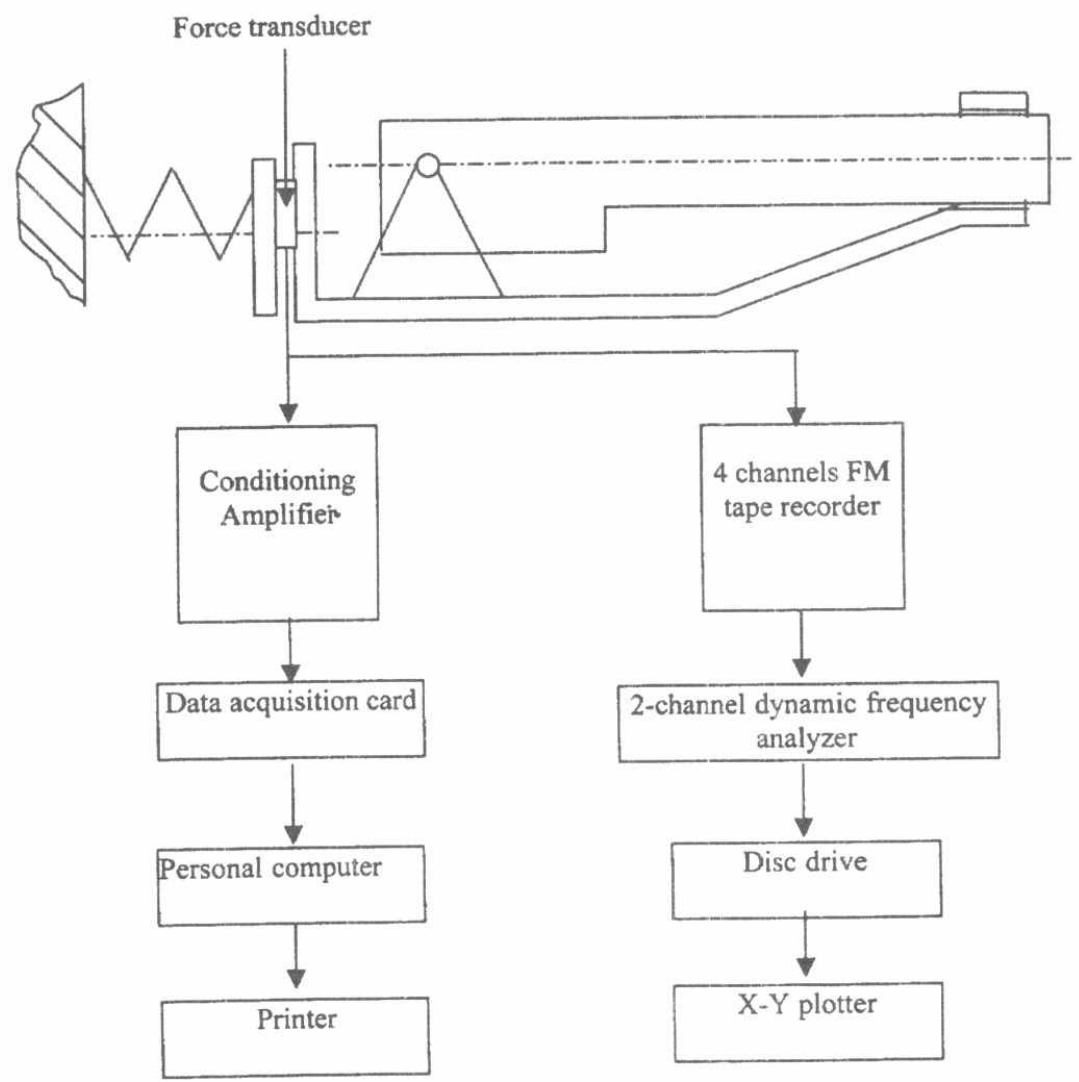

Fig. 3 Block diagram of the measuring system and instrumentations

\section{3- RESULTS AND ANALYSIS OF RECORDS:}

As the recoil force recorded within time duration of $100 \mathrm{~ms}$, this time is considered such that the record covers the phenomena during a full characteristic cycle of the weapon, considering this period of time makes the signal including all the dynamic responses taking place, while the tape recorder and the analyzer record the same event but with different resolutions, as the above signal recorded as an output of the force pick up. These records allow focusing on different activities taking place during firing, it also focuses on the position and time of maximum recoil force.

The repeatability of records either from the data acquisition system or the tape recorder; working with the multi-channel oscilloscope; proves the credibility of 
records. Applying the records as shown in Fig. 4 and Fig. 5, the analysis reveal the following main points:

*Every time the recoil force varies slightly during the period of time $t_{1}$, this force corresponds to the excitation generated from the impact of mechanical hammer which affects the system axially in forward direction. At the same time; the peak recorded during this period of time is related to the force of gases branching at the gas unit, the amplitude of which reaches $400 \mathrm{~N}$.
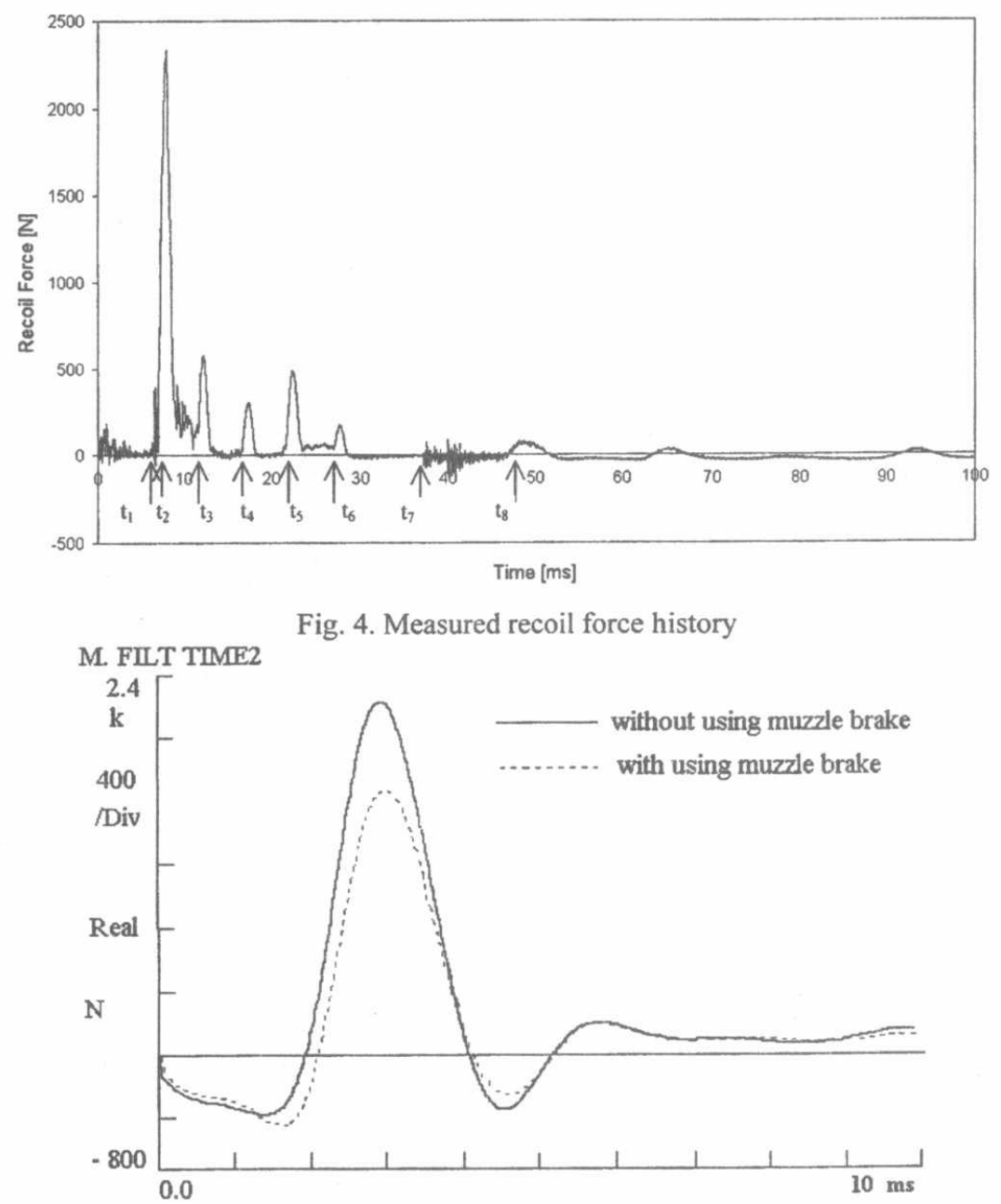

Fig. 5. Effect of muzzle brake on the recoil force 
*At time $t_{2} \approx 8 \mathrm{~ms}$; the projectile exits the muzzle affecting the whole system with recoil force of amplitude $\approx 2400 \mathrm{~N}$, this force recorded at $2^{\text {nd }}$ peak represents the maximum impulsive recoil force, this force approximately equals in magnitude to the momentum of projectile leaving the muzzle with value $(\mathrm{mV})$

*At the third period, $\mathrm{t}_{3} \approx 12.5 \mathrm{~ms}$; revealing the impact at the end of under-slide track, and it has the amplitude $\approx 600 \mathrm{~N}$.

*The fourth period, $\mathrm{t}_{4} \approx 17 \mathrm{~ms}$, represents the impact due to unlocking of breech block at the beginning of its backward motion, and it possesses the value of force $\approx 300 \mathrm{~N}$.

*Fifth period; $t_{5} \approx 21 \mathrm{~ms}$, during which the impact due to extraction of empty cartridge case from the barrel takes place, and its value reaches $\approx 500 \mathrm{~N}$.

*Sixth period; $\mathrm{t}_{6} \approx 27 \mathrm{~ms}$, during which the impact due to ejection of empty cartridge case outside takes place, and its value reaches $\approx 150 \mathrm{~N}$.

*Seventh period; $\mathrm{t}_{7} \approx$ from 36 to $45 \mathrm{~ms}$, during which the impact of moving parts at the extreme rear position takes place, and its value alternate around $\approx 120 \mathrm{~N}$.

*Eighth period; $\mathrm{t}_{8} \approx 49 \mathrm{~ms}$, explains the impact of moving parts during start of their motion together; (breech block \& breech block carrier); and the peak of this impact records the magnitude of $150 \mathrm{~N}$ force.

The analysis of amplitudes of the impacts and their corresponding time reveals the activities taking place during the function cycle of an automatic weapon, according this precise determination of dynamic force taking place at each event; it allows the designer to design precisely the different weapon components instead of mislead due to errors in theoretical determination of their values. It also allows precise evaluation of the efficiency of muzzle brake, or even the performance of any additional muzzle device whenever used.

\section{CONCLUSION}

1-An approximate description of function cycle of weapons is possible analyzing the signals received from recording recoil force history, since all events of weapon mechanisms were clearly appear in the recorded signals of the measured recoil force.

2-Using a muzzle brake reduces the maximum longitudinal dynamic strain near the free end by about $24 \%$ and near the constrained end by about $6 \%$. In the case of dynamic circumferential strain, the reduction was $49 \%$ near free end and $8 \%$ near the constrained end. Moreover, the recoil force is reduced by about $28 \%$. 


\section{5- REFRENCES:}

[1] Dioh N., Ivankovic A., Leevers P.,Williams.J., "Stress wave propagation effects in Split Hopkinson pressure bar tests", Proceedings of the Royal Society of London Series a-Mathematical and Physical Sciences, Vol.449, No.1936, pp.187-204, 1995.

[2] Morchi S., "Computer modeling for the coupled stress waves and structural response", Comput. Struct. Vol.36, No.6, pp. 1019-1030, 1990.

[3] Fayed A., "Investigation of stress waves in barrels due to firing", M.Sc. thesis, M.T.C., Cairo, 1994.

[4] Celens E., and Plovie G., "Recoil of Small Arms", $17^{\text {th }}$ International symposium on ballistics, Vol. 2, 23-27, pp. 91-101, South Africa, March 1998

[5] Leonard R., and Budiansky B., "Travelling waves in beams", Langly field, Langly Aeronautical Laboratory, 1975.

[6] Abo-Elkhair M., Aboul M., and Fayed A., "Solution of the wave equation in weapon barrels due to firing", Proceeding of the $7^{\text {th }}$ Applied Mechanics and Mechanical Engineering Conference, 28-30 May, pp. 35-47, M.T.C. , Cairo, 1996.

[7] Smith G., "Numerical solution of Partial Differential Equations", Oxford University Press, London, 1995.

[8] Belivins R., "Formulae for natural frequency and mode shape", Van-Nostrand Reinhold Company, 1979.

[9] Popelinsky L., "Theory and Design of Small Arms", Printed lecture, M.T.C., Cairo, 1965.

[10] Richard L., Burden J., Douglas F. and Reynolds A., " Numerical analysis" , Prindle, Weber \& Schmidt, U.S.A., 1981.

[11] Zukas J., Nicholas T., et al ,"Impact dynamics", Wright Patterson Air Force Base, Ohio, U.S.A., 1981.

[12] Warken D., et al, "Excitation of gun barrel vibrations caused by projectile unbalance and barrel curvature", Journal of Ballistics, Vol.7, Douglas Documentation System, U.S.A., 1984.

[13] Hazony D.," Stress wave propagation when the elastic coefficients vary with depth", Journal of circuit systems and signal processing, Vol.18, No.1, pp. 27 42, 1999.

[14] Abo-El-khair M., El-Naggar M, and Bassiouni A., "Theoretical and experimental study of barrel Vibrations due to firing", M.Sc. thesis, M.T.C., Cairo, 1986. 